\title{
MENELUSURI JEJAK SEJARAH PENINGGALAN PORTUGIS DI KAMPUNG NUMBA
}

\author{
Hasti Sulaiman \\ Dosen Progam studi pendidikan Sejarah Universitas Flores \\ Email: hastiariswan@gmail.com \\ Fransiskus Xaverius Rema \\ Dosen Progam studi pendidikan Sejarah Universitas Flores \\ Email: remafransiskus@gmail.com \\ Anita \\ Dosen Progam studi pendidikan Sejarah Universitas Flores \\ Email: anitazafana@gmail.com
}

\begin{abstract}
Abstrak
Penelitian ini menelusuri sejarah awal kedatangan dan peninggalan Portugis di Kampung Numba, Kabupaten Ende Provinsi Nusa. Kajian ini menggunakan pendekatan historis dalam melihat persoalan. Untuk mendapatkan paparan data dan kesimpulan penelitian ini penulis memanfaatkan beberapa kesempatan dengan mengunjungi dan melihat langsung lokasi fokus penelitian. Data dikumpulkan dengan tehnik penelusuran sejarah Ende dari berbagai sumber kepustakaan, termasuk dari sumber internet mengenai gambaran NTT Secara umum. Hasil penelitian menunjukan bahwa kedatangan bangsa Portugis di kampung Numba tidak lepas dari persaingan dengan Islam di Pulau Ende. Sebelum Potugis berpindah dari pulau Ende ke pesisir selatan pulau Flores pada tahun 1620-1630 terjadi penyerbuan kepada orang Portugis yang saat itu berada di dalam benteng. Dari beberapa sumber informasi terpercaya melalui ingatan dan cerita lokal yang masih berkembang dapat dibuktikan bahwa kedatangan Portugis di kampung Numba meninggalkan jejak sejarah dalam bentuk fakta-fakta sejarah secara fisik. Bukti-bukti peninggalan Portugis diantaranya: perigi, meriam, dan gereja, makam dari seorang uskup serta patung bunda Maria. Walaupun bukti fisik beberapa peninggalan sejarah ini sudah tidak terawat lagi, namun menjadi bagian penting dalam dinamika sejarah yang oleh warga setempat masih terus dikisahkan karena merupakan bagian dari sejarah masyarakat setempat akan masa lampaunya.
\end{abstract}

Kata kunci : Sejarah, Peninggalan Portugis, kampung Numba

\begin{abstract}
This study traces the history of the arrival and the Portuguese legacy in Numba Village, Ende Province Nusa Province. This study uses a historical approach in looking at problems. To get the data exposure and conclusions of this study the authors take advantage of several opportunities by visiting and seeing firsthand the location of the research focus. Data was collected with Ende historical search techniques from various library sources, including from internet sources on the general description of NTT. The results showed that the arrival of the Portuguese in the village of Numba was inseparable from competition with Islam on Ende Island. Before Potugis moved from the island of Ende to the southern coast of the island of Flores in 1620-1630 there was an attack on the Portuguese who were then inside the fortress. From some reliable sources of information through the memories and local stories that are still developing, it can be proved that the arrival of the Portuguese in the village of Numba left a historical trail in the form of physical historical facts. Evidence of Portuguese relics include: teeth, cannons, and churches, the tomb of a bishop and a statue of Mary. Although the physical evidence of some of these historical relics is no longer maintained, it is an important part of the dynamics of history that local people continue to tell because it is part of the history of the local community for its past.
\end{abstract}

Keywords: History, Portuguese Relics, Numba village. 


\section{PENDAHULUAN}

Sejarah adalah ilmu yang mempelajari kejadian atau peristiwa di masa yang lampau untuk dijadikan pedoman pada masa sekarang dan masa yang akan datang. Dalam kaitannya dengan sejarah, Sartono Kartodirdjo (2005) memandang bahwa sejarah adalah cerita tentang pengalaman kolektif suatu komunitas suatu bangsa di masa lampau yang akan membentuk kepribadian nasional dan sekaligus menentukan identitas nasional bangsa tersebut. Seorang yang mempelajari sejarah, pada gilirannya akan memiliki wawasan sejarah. Dengan memiliki wawasan sejarah, seseorang akan dapat mengkonsepkan sejarah yang berguna untuk mengantisipasi masa depan, termasuk di dalam pembangunan bangsa. Dengan demikian cerminan sejarah dapat dijadikan sebagai objek dalam barometer pembangunan bangsa yang bermartabat, beradab, dan berkearifan sosial budaya.

Sejarah juga merupakan jalan menuju pemahaman atas berbagai pengalaman hidup manusia yang memiliki makna sejarah. Dalam kaitannya dengan pemahaman akan sejarah bangsa, maka sejarah bangsa Indonesia juga mengambil bagian dari perjalannan panjang sejak bangsa ini ada, berkembang dengan adanya kerajaan-kerajaan, sampai sejarah yang tidak mengabaikan kolonialisme dan imperialisme bangsa Eropa di Bumi Nusantara seperti Portugis, Spanyol, Belanda, Jepang dan Inggris.

Kedatangan bangsa Barat ini tentunya akan meninggalkan jejak sejarah tentang keberadaan mereka di suatu wilayah. Dengan demikian pengetahuan akan sejarah ini yang dimaksud dalam tulisan ini adalah adanya keinginan dalam menelusuri jejak kedatangan Bangsa barat di Asia Tenggara hingga ke pelosok Nusantara. Sebelum akhirnya berlabuh di suatu wilayah yang namanya Pulau Ende dan pesisir Selatan pulau Flores yaitu di kampung Numba kecamatan Nangapanda, kabupaten Ende-Flores Nusa Tenggara Timur, bangsa Spanyol telah melakukan perjalanan yang panjang dari Malaka, Maluku, Larantuka, dan lain sebagainya.

Pulau Ende pada masa lalu menjadi salah satu daerah tujuan (transito) para pedagang dan pelayar dari Jawa, Makasar, dan Ternate. Karena menjadi salah satu titik transit para pedagang, maka sejarah keagamaan dan kepentingankepentingan kolonialisme bermain di daerah-daerah pelabuhan seperti pulau Ende. Kasus-kasus seperti ini tidak hanya terjadi di pulau Ende namun juga di Lahayong (Solor, Flores Timur), Pulau Alor, dan Kupang yaitu pelabuhanpelabuhan yang terkenal di Nusa Tenggara Timur pada masa lalu 
(Murtadho,2015:238). Sejalan dengan maksud yang tersebut di atas, maka dapat dibuktikan bahwa perkembangan perdagangan dengan berbagai dinamika yang diterima dipesisir telah terjadi kontak signifikan dan membuka isolasi daerah pedalaman di nusantara umumnya dan NTT khususnya.

Penelusuran akan sejarah kontak dengan dunia luar dimulai pada abad keXVI tampilah berbondong-bondong pedagang-pedagang bangsa Eropa di Asia Tenggara. Mereka datang bukan sebagai perseorangan, tetapi datang sebagai kekuasaan. Adapun awal kedatangan bangsa Eropa ke wilayah Asia Tenggara adalah berdagang. Tetapi demi kepentingan perdagangan itu mereka segera menanamkan pengaruh dan kekuasaannya yang lebih tegas diberbagai tempat di Asia Tenggara.

Dimulainya perdagangan di pelabuhan Ende telah tercatat sejak tahun 1660 yaitu hubungan antara Ende, Raja Makassar, dan VOC. Setelah perang usai pada tanggal 18 November 1667, Admiral Cornelis Spelman memperbarui hubungan dagang tersebut. Sejak saat itu pihak Belanda (VOC) membangun posthouder Barai di daerah pesisir Teluk Ende (Irshanto,2016:74).

Aktivitas perdagangan bangsa Eropa yang disertai dengan kekuasaan itu terasa paling terutama pada di kepulauan Asia Tenggara (semenanjung Malaka dan Indonesia), bangsa Portugis adalah Bangsa Eropa pertama yang tiba dikepulauan tersebut. Karena wilayah ini merupakan tempat yang menjadi tujuan utama perdagangan mereka untuk menguasai rempah-rempah yang nilainya sangat berharga dan bangsa Portugis pula yang pertama kali merubag perkembangan dari perdagangan menjadi kekuasaan politik, meskipun masih terbatas.

Bangsa Portugis untuk pertama kalinya di Asia Tenggara pada tahun 1509, di kota kerajaan Malaka, mereka datang dalam rangkaian perang salib terhadap kaum muslim, tetapi terutama mencari keuntungan yang lebih besar dari perdagangan lada dan rempahrempah. Pada tahun 1511 bangsa Portugis menyerang Malaka dan selanjutnya mendudukinya, dengan maksud menguasai lada dan rempahrempah yang mengalir ke dunia Barat yang titik pangkalnya adalah kota kerajaan Malaka itu. Hall (1988)

Pada tahun 1512, Bangsa Portugis dibawa pimpinan De Abreau, berlayar menuju Maluku, dan dalam pelayaran Bangsa Portugis juga singgah di beberapa pelabuhan seperti Aceh, Banten, Sunda Kelapa, Cirebon, Demak, Gresik dan akhirnya sampai ke Ternate. Di Ternate Portugis berhasil mendirikan Benteng yang Benama "Sao Paolo" Dengan kedatangan bangsa Belanda pada tahun 1596 di Asia Tenggara, perdagangan Portugis segera 
terdesak dan akhirnya Malaka jatuh ke tangan Belanda pada tahun 1641, dan Portugis terusir dari wilayah Maluku. Kemudian bangsa Portugis berlayar ke wilayah Indonesia bagian timur yaitu Nusa Tenggara Timur (Kepulauan Sunda kecil) tepatnya di pulau Timor. Kedatangan bangsa Portugis di Nusa Tenggara Timur pada tahun 1556 pertama kali tiba di pulau Solor, kemudian memusatkan perdagangannya disekitar pulau Solor, hal tersebut dilakukan agar terlindungi dari serangan penduduk yang beragama Islam dan para bajak laut. Para pedagang Porugis berhasil mendirikan sebuah benteng dipulau Solor pada tahun 1566 (I. H. Doko).

Pengaruh Portugis dalam menyebarkan agama Katolik mulai terlihat ketika misi Katolik mulai diatur dengan kehadiran Uskup pertama Jorge de Santa Luzia OP di Malaka pada tahun 1561. Portugis mengirim tiga orang misionaris Dominikan pertama ke Solor dan tahun 1566 pastor Antonio Da Cruz membangun sebuah benteng di pulau Solor dan sebuaah seminari di dekat kota Larantuka. Dari Solor dan Larantuka inilah titik awal sejarah agama Katolik berkembang di Flores dan Timor hingga saat ini. Di akhir abad ke16 agama katolik telah meluas dan diperhitungkan sekitar 25.000 penganut dan populasi pengikut terbesarnya adalah berada di Solor, Adonara,
Flores. (Http: / Zima Multy Media 2017). Melalui perkawinan antara serdadu dan pedagang Portugis dengan penduduk asli timbullah disana suatu golongan IndoPortugis yang beragama kristen yang kemudian di dalam sejarah dikenal dengan nama "Topasses" atau Portugis hitam. (I. H. Doko. 1973 :20).

Bangsa Portugis melakukan perdagangan di wilayah Nusantara untuk kejayaan bangsanya di samping itu juga mereka mempunyai misi untuk menyebarkan ajaran nasrani disetiap daerah yang disinggahinya, mulai dari Maluku, terus menelusuri daerah-daerah lain dalam wilayah Nusantara seperti Demak, Aceh, Ambon, Ternate, Tidore, Solor, Timor dan Flores. Pada bulan Desember 1521 kapal Victoria berangkat dari Ambon dan tiba di sebeleh Timur pulau Flores dan daerah-daerah yang disinggahi Portugis adalah Larantuka, Sikka, Paga dan terusnya ke arah pantai selatan yaitu Pulau Ende, Kewa, Laka, Mari, Tonggo, Lambo, Lena (Uran, 1995: 34).

Tepatnya pada tahun 1562-1601 bangsa Portugis masuk di Pulau Ende, keberadaan Portugis di Pulau Ende, sangat mepengaruhi kehidupan masyarakatnya hal ini terlihat jelas dalam bidang religi dan kebudayaan, (Uran, 1995 : 24). Dalam bidang religi, bangsa Portugis melakukan permandian terhadap masyarakat umat katolik, menyebarkan agama katolik, mendirikan 
Stasi yakni di kampung Saraboro, Curo Laras yang sekarang dikenal dengan kampung Kuraro, serta di kampung Numba, dan dalam hal kebudayaan, Portugis bersama masyarakat setempat berhasil mendirikan sebuah benteng guna melindungi diri dari serangan penduduk yang beragama Islam, orang Jawa dan para bajak laut.

Yang menarik perhatian peneliti dengan kedatangan Portugis ini adalah peninggalan Portugis di kampung Numba yang sampai detik ini masih ada sisa peninggalannya. Namun hanya segelintir orang yang mengetahuinya. Lebih jauh tujuan penelitian ini adalah guna menjaga atau melestarikan peninggalan sejarah tersebut agar tidak punah.

\section{METODE PENELITIAN}

Penelitian ini dilakukan di Kampung Numba Kabupaten Ende Provinsi Nusa Tenggara Timur pada bulan Januari- Maret 2017. Pengumpulan data dilakukan dengan studi pustaka, observasi, dan wawancara semi struktur dengan beberapa tokoh masyarkat yang dengan ingatannya mampu merangkaikan beberapa hal yang diingatnya tentang sejarah masa lampau.

Metode dalam penelitian ini menggunakan metode historis. Metode penelitian historis adalah metode yang digunakan sebagai pedoman dalam melakukan penelitian peristiwa sejarah dan permasalahannya. Dengan kata lain, metode penelitian sejarah adalah instrumen untuk merekonstruksi peristiwa sejarah (history as past actuality) menjadi sejarah sebagai kisah (history as written). Dalam ruang lingkup sejarah, metode penelitian ini disebut metode penelitian sejarah. Dalam metode penelitian sejarah terdapat empat tahapan yang harus dialakukan oleh seorang peneliti yaitu heuristik, kritik, interpertasi dan historiografi. Pertama heuristik (heuristic) yaitu mengumpulkan atau menemukan sumber. Yang dimaksud dengan sumber atau sumber sejarah (historical sources) yaitu sejumlah materi sejarah yang tersebar dan teridentifikasi. (L. Gottschalk dalam Suhartono, 2010: 29). Lebih jelasnya seperti apa yang dikatakan Carrad bahwa heuristik adalah merupakan langkah awal sebagai sebuah kegiatan mencari sumber-sumber, mendapatkan data atau materi sejarah atau evidensi sejarah. (Sjamsudin, 2007:86). Kedua Kritik Sumber sejarah/ Verivikasi setelah sumber sejarah sudah terkumpul, tahap berikutnya adalah Verivikasi atau yang biasa disebut dengan kritik untuk meperoleh keabsahan sumber. Dalam hal ini yang juga harus diuji adalah keabsahan tentang keaslian sumber (otensitas) yang dilakukan melalui krtik ekstern, dan keabsahan tentang kesahian sumber 
(kredibilitas) yang melalui kritik intern. (wikipedia, 2017). Ketiga interpertasi Interpertasi atau penafsiran data sejarah sering juga disebut analisis sejarah. Lebih jelasnya bahwa interpertasi data atau analisis data adalah proses mencari dan menyusun secara sistematis yang diperoleh dari hasil wawancara, catatan lapangan dan dokumentasi dengan cara mengorganisasikan dalam kategori, menjabarkan ke dalam unit-unit, melakukan sintesa, menyusun ke dalam pola, memilih mana yang penting dan yang akan dipelajari dan membuat kesimpulan sehingga mudah untuk dipahami oleh diri sendiri maupun orang lain (Sugiyono, 2008:244). Keempat Historiografi Sebagai tahapan terakhir dalam penulisan sejarah, historiografi ini merupakan cara penulisan, pemaparan atau pelaporan hasil penelitian sejarah yang telah dilakukan sehingga tersusun suatu berita sejarah yang sistematis

\section{PEMBAHASAN}

\section{Kedatangan Portugis di Numba}

Pembahasan tentang keberadaan Portugis di Ende di awali dengan kerajaan Ende. Eksistensi kerajaan Ende dalam dokumen Kolonial diketahui bahwa pada tahun 1703 melalui VOC atau Belanda adalah yang pertama kali mengadakan korte verklaring dengan kerajaan Ende. Peristiwa Korte
Verklaring ini menjadi bukti resmi dari versi administrasi modern khas kolonial; pengakuan adanya kerajaan Ende di Flores. Namun berdasarkan data-data di lapangan, keberadaan kerajaan Ende diperkirakan lebih dahulu ada sebelum tahun dimaksud. Kerajaan Ende hadir kurang lebih bersamaan dengan terusirnya Portugis dari pulau Ende pada tahun 1630 dan dimulainya peradaban baru Ende daratan (Murtadho, 2015:242243)

Peradaban Ende daratan inilah kemudian melahirkan perkampungan di pesisir selatan pulau Flores salah satunya adalah kampung Numba. Terlebih dahulu peneliti dapat mendeskripsikan lokasi dimana posisi atau letak dari Numba. Numba adalah sebuah wilayah kampung yang berada di kabupaten Ende, salah satu kota kabupaten di Nusa Tenggara Timur, yang letaknya dibagian selatan dari pulau Flores. Jarak tempuh antara kota kabupaten dengan kampung Numba kurang lebih $19 \mathrm{~km}$. Numba merupakan daerah yang letaknya di pesisir pantai dan merupakan daerah teluk. Daerah teluk ini adalah salah satu daya tarik dari bangsa Portugis untuk dijadikan tempat pengungsian karena nyaman dari gelombang laut sebagai tempat bersandarnya kapal.

Sejarah tentang wilayah yang menjadi daerah peninggalan sejarah di Indonesia oleh Portugis ini dikategorikan 
dalam sejarah lokal. Sampai sekarang belum ada rumusan yang memuaskan tentang apa Sejarah lokal, Menurut : H.P.R. Finberg (Sejarawan Inggris) dalam bukunya Lokal History, Obyektive And Pursuit tidak ada yang mengemukakan yang lebih eksplisit. Namun demikian disini bisa mencoba memulai dengan rumusan sederhana, yaitu: Sejarah lokal bisa dikatakan sebagai suatu bentuk penulisan sejarah dalam lingkup yang terbatas pada lokalitas tertentu, jadi terbatas lingkup terutama dikaitkan dengan dengan unsur wilayah.

Menurut Taufik Abdullah sejarah lokal adalah suatu peristiwa yang terjadi di tingkat lokal yang batasannya dibuat atas kesepakatan atau perjanjian oleh penulis sejarah. Batasan lokal ini menyangkut aspek geografis yang berupa tempat tinggal suku bangsa, suatu kota, atau desa (Abdullah, 1982).

Ahli lain mengatakan bahwa sejarah lokal adalah bidang sejarah yang bersifat geografis yang mendasarkan kepada unit kecil seperti daerah, kampung, komunitas atau kelompok masyarakat tertentu (Abdullah, 1994: 52). Suatu peristiwa yang terjadi di daerah yang merupakan imbas atau latar terjadinya peristiwa nasional.

Dalam cerita lokal setempat bahwa awal pengusiran Portugis dari Pulau Ende dipicu adanya peristiwa putri Rendo yang karena cerita asamara terpaksa terusir dari pulau Ende dan meninggal dalam pelariannya. Hal ini menyebabkan orang Barai (asal putri Rendo tersinggung dan melakukan penyerangan ke pulau Ende. Penyerangan ini dipelopori oleh Jari Jawa jago lokal setempat. Terlepas dari cerita lokal di atas bahwa di Ende daratan pada saat itu telah terjalin suatu kekuatan yang siap menghancurkan kekuatan Portugis di Pulau Ende. Kisah putri Rendo hanya pintu masuk terjadinya Clash antara orang Ende dengan orang Portugis di Ende. Semangat perlawanan saat itu menjadi bagian semangat nusantara untuk mengusir Portugis dari neggeri yang nantinya bernama Indonesia (Murtadho,2015:244). Hal ini telah mencirikan sejarah lokal dalam cakupan sejarah secara nasional. Dengan demikian, dalam pandangannya Wasino (2009: 2) mengatakan bahwa sejarah lokal adalah sejarah yang posisinya kewilayahannya di bawah sejarah nasional. Sejarah baru muncul setelah adanya kesadaran adanya sejarah nasional. Namun demikian bukan berarti semua sejarah lokal harus memiliki keterkaitan dengan sejarah nasional. Sejarah lokal bisa mencakup peristiwaperistiwa yang memiliki keterkaitan dengan sejarah nasional dan peristiwaperistiwa khas lokal yang tidak berhubungan dengan peristiwa yang 
lebih luas seperti nasional, regional, atau internasional.

Di Indonesia disamping istilah sejarah lokal, dikenal juga dengan istilah daerah. Sehingga istilah sejarah lokal dan sejarah daerah digunakan seringkali berganti-ganti tampa penjelasan yang tegas. Lokal dan daerah secara harfiah memiliki arti yang sama, tetapi dalam kajian sejarah banyak digunakan istilah lokal. Dengan pertimbangan daerah selalu berkonotasi politis (adanya stratifikasi pusat dan daerah: DATI I dan II) sehingga lebih digunakan bahasa lokal karena lebih netral dan tidak brkonotasi politis. Sedangkan pengertian regional dan nasional. Regional secara internasional Negara yang berada dalam lingkup regional disebut lokal. Contoh asia tenggara: Indonesia, Vietnam,dll. Dengan demikian, secara sederhana dapat dikatakan bahwa sejarah lokal adalah bidang kajian mengenai masa lalu dari suatu kelompok atau masyarakat yang mendiami unit wilayah yang terbatas.

Belum berakhirnya kekuasaan Portugis di Pulau Ende muncul bangsa Belanda. Pulau Ende saat itu sangat penting karena diperebutkan oleh Portugis dan Belanda. Selain letaknya strategis untuk menyerang Ende dari laut, ditambah waktu itu Belanda dapat menaklukan Portugis di Ambon, maka pengaruh Belanda kemudian bertambah termasuk Pulau Ende yang kemudian diperebutkan oleh kedua bangsa Eropa tersebut. Menyusul pada 1613 juga dilakukan pengusiran orang Portugis dari pulau Solor oleh Belanda. Hanya orang Portugis tertentu yang diberi izin tetap tinggal dipulau Solor terutama beberapa imam Katolik.

Sejak 1613 bersamaan diusirnya orang Portugis dari pulau Solor oleh orang Belanda, hal ini juga terjadi di pulau Ende juga dibawah kekuasaan kompeni Belanda. Semua bekas Portugis di Pulau Solor termasuk pulau Ende diganti dengan nama Belanda.

Pada waktu itu komandan benteng Hendricus Solor Adrian Van der Velder mengunjungi pulau Ende ia ingin mendamaikan penduduk yang beragama Islam dan Katolik. Memerintahkan agar benteng Portugis di Numba dihancurkan tetapi ditolak oleh penduduk Ende. Kemudian D Cosmo datang dari Sikka ke pulau Ende memperbaiki benteng yang tujuannya adalah mengusir orang Islam dari pulau Ende.

Pada Juli 1614 komandan Adrian Van der Velde mengunjungi Pulau Ende, sewaktu ia kembali dari pulau Solor. Dalam kunjungan kedua ini ia mencegah hubungan kerja sama antara pulau Ende dengan Portugis. Dan di pulau Ende ia menemukan tidak ada imam katolik disana. Hanya tiga kepala keluarga yang memelihara iman penduduk pulau Ende yang katolik. Ketiga kepala keluarga itu 
diculik di bawah ke sebuah kampung di Ende-Flores yang diberinama Volumavo atau yang dikenal dengan Wolowona sekarang. Karena mereka tidak mau melepaskan imannya, akhirnya dianiaya dijemur dipanas matahari dipukul serta ditusuk sekujur tubuhnya dengan benda tajam akhirnya ketinganya meninggal dan dikuburkan di Wolowona, ketiga penduduk asli pulau Ende adalah Salvador Carvalhaes (28) tahun, bekas siswa seminari Kolese Dominikan stasi Solor, Pedro Carvalhaes (40) sudah berkeluarga keduanya berasal dari Numba- Pulau Ende sedangkan yang ke tiga adalah Manuel da Lima dari paroki Saraboro-Pulau Ende.

Setelah penganiayaan terhadap penduduk asli pulau Ende dikirim pula dua orang yakni P. Chrisostomo do Rosario untuk stasi Numba dan P. Agustinho untuk stasi Saraboro. Menurut catatan GP Roffaer tentang benteng pulau Ende dalam Nederland Indie oud en Nieuw pada tahun 1561-1638 dikatakan terjadi pengusiran terhadap Portugis pada 1620-1630 penyebabnya adalah pemerkosaan atas gadis kampung pulau Ende oleh seorang juru bahasa Portugis. (Uran ,1961)

Pembunuhan para pemuka katolik itu merupakan siasat kotor dari Belanda untuk melumpuhkan daya tahan dari agama katolik, Belanda yang menggalakan orang Islam untuk melumpuhkan Portugis yang beragama kristiani. Karena Belanda penganut Calvinisme, memusuhi agama katolik yang dianut dan disebarkan oleh bangsa Portugis. Keruntuhan pengaruh politik, ekonomi Portugis melibatkan juga agama katolik dan misionaris. Belanda memperalat Islam dengan mempertajam pertentangan- pertentangan, dengan demikian penduduk pulau Ende yang beragama Katolik dan yang beragama Islam dilibatkan dalam pemberontakan besar pada tahun 1620- 1630 yaitu terjadi pembunuhan semua orang Portugis di benteng, karena takut balas dendam Portugis, penduduk akhirnya mengungsi ke pantai teluk Ende.Kedatangan Portugis di kampung Numba tidak terlepas dari kedatangan Portugis di pulau Ende yang merupakan salah satu pulau utama yang dikuasai Portugis untuk merebut Ende daratan. Pulau Ende sebuah pulau kecil yang memanjang yang terletak di teluk Ende menjadi pusat kegiatan Portugis dan agama katolik sejak akhir abad ke-14. Pulau Ende awalnya sudah ada penduduk umumnya berasal dari Goa Sulawesi Selatan. Pulau Ende pada saat itu banyak menghasilkan kayu Cendana selain di Timor, gaharu, kayu manis, rempah-rempah meskipun jumlahnya tidak sebanyak di Ambon. Daya tarik Portugis adalah hasil tanam itu yang sangat terkenal hingga ke Eropa lewat Malaka atau Malaya (Malaysia sekarang). Malaka direbut oleh Portugis pada dari 
pedagang Arab pada tahun 1615 dari Malaka Portugis terus ke timur ke kepulauan Ambon, Ternate Key Tanimbar selanjutnya ke tenggara ke kepulauan Pantar, Solor, Adonara dan Flores.

Pulau Ende pada saat itu dihuni penduduk mayoritas beragama katolik karena dipengaruhi oleh Portugis sesekali diserang oleh pedagang dari pulau Jawa dan Makasar Goa tujuannya adalah mengusir Portugis. Pada tahun 1605 keadaan pulau Ende semakin genting karena banyak pengungsi dari Solor mempengaruhi penduduk pulau Ende agar berontak terhadap Portugis. Pada tahun 1605 terjadi pemberontakkan yang cukup menggemparkan antara penduduk yang dipengaruhi oleh orang Jawa dan Makasar dengan penduduk yang dipengaruhi oleh orang Portugis, namun catatan mengenai peperangan tersebut yang banyak kehilangan nyawa dan harta benda tidak ada dalam catatan resmi Indonesia semua tersimpan di arsip Amsterdam -Belanda hanya peminat sejarah saja yang tahu.

Belum berakhirnya kekuasaan Portugis di Pulau Ende muncul bangsa Belanda. Belanda dan Portugis bersaing memperebutkan Pulau Ende. Baru pada abad ke -19 ketika kondisi sudah mulai kondusif dan Belanda (VOC) sudah menguasai laut Sawu dari tangan Portugis maka VOC memberanikan diri untuk membuka pelabuhan Ende secara resmi untuk lalu lintas perdagangan pada tahun 1839. Sejak saat itu kegiatan perdagangan dan pelayaran mengalami peningkatan dibandingkan pada periode sebelumnya. Dengan demikian kapal layar tradisional tak lagi mendominasi tetapi didominasi oleh kapal-kapal api milik para investor yang membawa barang ekspor dan impor (Irshanto,2015:75)

Dalam perjalanan sejarah ternyata Belanda yang menggalakan orang Islam untuk melumpuhkan Portugis yang beragama kristiani. Karena Belanda penganut Calvinisme, memusuhi agama katolik yang dianut dan disebarkan oleh bangsa Portugis. Keruntuhan pengaruh politik, ekonomi Portugis melibatkan juga agama katolik dan misionaris. Belanda memperalat Islam dengan mempertajam pertentangan- pertentangan, dengan demikian penduduk pulau Ende yang beragama Katolik dan yang beragama Islam dilibatkan dalam pemberontakan besar pada tahun 1620- 1630 yaitu terjadi pembunuhan semua orang Portugis di benteng, karena takut balas dendam Portugis, penduduk akhirnya mengungsi ke pantai teluk Ende. Lalu muncul kampung-kampung besar di pantai teluk Ende pada abad ke-17 antara lain Brai, Kuraro, Saraboro dan Numba. Agama Katolik untuk sementara terpelihara di Saraboro dan juga di 
Numba yaitu di kota Kori. Dalam pengungsian mereka diikuti oleh Herenimo de Santiago untuk merawat kepentingan pastoral mereka. Di Saraboro dan Numba cukup lama menganut agama katolik sampai pada tahun1722 ketika ditinggalkan oleh Portugis. Walaupun Numba cukup lama menganut katolik namun untuk masa sekarang hampir tidak tersisa kenangan dari zaman lampau, kecuali sebagian orang Numba sejak peristiwa berdarah mereka mengungsi ke Sikka dan sampai hari ini tetap menganut Katolik. (hasil wawancara dengan bapak Ahmad Pua To).

Berita tahun 1872 oleh S. Roos, seorang kepala kampung Numba yang berusia lima puluh tahun menceritakan, bahwa orang Portugis terakhir berangkat dari Numba agama katolik masih bertahan lama walaupun tidak murni lagi, setelah kematian pemuka-pemuka agamanya, alat-alat ibadah hilang dan agama katolik perlahan-lahan berakhir. Kemudian penduduk Numba memeluk Islam karena dipengaruhi oleh orang Makasar-Goa dan juga oleh Islam dari Ende.

Pada tahun 1882 ketika Numba dikunjungi oleh Pastor Sikka Lecoque de Armanville dia tidak menemukan bahwa ada tanda-tanda bahwa orang Numba masih memeluk agama Katolik. Ia membawa bendera Portugis dari Sikka ke Numba untuk memperbaharui ikatan keluarga dan ikatan agama dari zaman lampau. Diakakui hubungan kekeluargaan antar Numba dan Sikka, tetapi mengaenai agama tidak dilaporkan kecuali ia sempat mempermandikan sembilan anak-anak di Numba dan empat puluh anak di Maurongga.

Tahun 1914 ketika pastor dari Larantuka mengunjungi Ende beberapa waktu lamanya karena urusan kesehatan dan merayakan paskah dengan 63 orang Katolik asal Larantuka dan Sikka serta empat orang Eropa, namun tidak mengunjungi bekas pulau katolik yakni pulau Ende dan bekas katolik Numba. Jadi Numba tidak memberikan harapan umtuk perawatan pastoral. Inilah kekalahan total bagi agama katolik dan kemenangan mutlak bagi agama Islam di Pulau Ende dan Numba.

\section{Peninggalan Portugis di Kampung Numba}

Kehadiran Portugis di pulau Ende dan kampung Numba diperkirakan berlangsung selama kurang lebih 39 tahun dari tahun1562-1601. Keberadaan bangsa Portugis di Numba salah satu misinya adalah menyebarkan misi sucinya yaitu penyebaran agama Katolik, namun gagal, Portugis mengalami kekalahan total, karena kemenangan mutlak dari para penyerang yang beragama Islam. Meskipun demikian bangsa Portugis juga 
meninggalkan beberapa situs kenangan bersejarah. Ada beberapa bukti peninggalan Portugis di Kampung Numba meskipun hampir hilang karena dimakan zaman, diantaranya : terdapat sebuah Meriam besi di kampung Numba, yang sampai sekarang masih ada dan dalam kondisi utuh, namun sudah berkarat, beratnya kurang lebih $100 \mathrm{~kg}$. Meriam tersebut dibawa dari pulau Ende, karena pada saat itu terjadinya pertempuran. Dalam sejarah tentang bebebrapa benteng Portugis di beberapa wilayah, meriam selalu menjadi bagian penting karena merupakan senjata mematikan bagi lawannya. Keperkasaan benteng dapat ditunjukan dengan beberapa meriam di sisi depan bentengnya.

pada saat yang sama maka terjadilah pengungsian ke kampung Numba. Setelah bermukim beberapa waktu di kampung Numba, bangsa Portugispun dalam misinya kemudian mendirikan sebuah gereja diwilayah itu yang diberinama “Antonius Dominikus”. Gereja dalam perkembangannya rupanya mengalami kelesuan yang luar biasa dalam mengembangkan misi rohaninya karena bebrbagai tantangan dari dalam masyarakat sendiri yang saat itu memang sudah menyisakan luka yang begitu mendalam terhadap Portugis sehingga tidak bisa berjalan dengan normal. Kondisi masyarakat yang tertekan saat itu dan kebencian terhadap Portugis akan masalah terdahulu yang menyebabkan agama katolik tidak mampu berkembang diwilayah tersebut.

Walaupun mengalami masalah sulit namun gereja tetap dijaga dan dirawat oleh seorang uskup Hermino de Santiago di kampung Numba penganut katolik yang paling lama, namun pada hari ini tidak satupun masyarakat kampung Numba yang menganut agama katolik. Gereja yang ditinggalkan oleh bangsa Portugis masih ada bekas dindingnya sampai hari ini, meskipun tidak utuh lagi, karena ditutupi oleh longsoran tanah disebabkan letaknya berada bagian bawah bukit.

Menurut informasi yang diperoleh dari bapak Ahmad Pua To, pada jaman dahulu di dalam gereja ada perlengkapan peribadatan umat katolik. salah satunya adalah patung Bunda Maria. Patung merupakan bagian penting yang ditempatkan di dalam gereja, namun saat ini sudah tidak ada bukti fisiknya di kampung Numba, karena kemungkinan sudah dijual oleh "Seda Malu Batambo" anak dari penguasa Numba (Raja Batambo). Belum diketahui secara pasti kenapa patung Bunda Maria berpindah ke daerah pegunungan Numba yang bernama "Keppi" yang merupakan keseluruhan penduduknya beragama katolik. Menurut informasi, Patung Bunda Maria masih ada sampai sekarang, namun keterbatasan peneliti untuk menjangkau 
ke daerah tersebut dan sumber informasi yang menyertainya menyebabkan hal ini menjadi misteri.

Ada peninggalan lain, yaitu sebuah makam atau kubur yang ditandai dengan salib. Untuk wilayah dan penduduk setempat yang semuanya berpenganut muslim saat ini hal ini menjadi suatu keunikan. Diduga makam dari Uskup Hermino de Santiago berkebangsaan Portugis. Makam ini berada di atas bukit perkampungan Numba yang jaraknya tidak jauh dari keberadaan bekas gereja tersebut. Sudah menjadi kebiasaan umum dalam kepemimpinan gereja Katolik bagi pemimpin gereja dengan menguburkan gembalanya di dekat gereja agar bisa dikenang. Kondisi makam ini sama halnya dengan keadaan bekas gereja yang sama-sama tidak dirawat.

Sama halnya dengan beberapa bukti yang masih tersisa lainnya, Perigipun merupakan saksi bisu sejarah tentang eksistensi Portugis yang pernah mendiami daerah tersebut. Perigi terletak di sekitar sungai yang kering, yang jaraknya sekitar 50 meter dari pantai, perigi ini merupakan sumber air bagi kehidupan bangsa Portugis selama berada di kampung Numba. Ditinjau dari letak sumur tersebut, merupakan pintu masuk bangsa Portugis dari Pulau Ende menuju daratan Ende yaitu di Kampung Numba.
Menurut hasil wawancara dengan bapak Ahmad Pua To, di sekitar perigi tersebut terdapat belahan cangkang kerang besar, yang diduga sebagai wadah untuk menampung air dan kerang tersebut masih ada dan tetap utuh sampai sekarang. Dan di dinding perigi tertulis nama "Adonara" kesimpulan yang ditarik oleh peneliti adalah, penggalian perigi ini kemungkinan dengan mendatangkan orang yang berasal dari Adonara selain membantu di dalam benteng juga sebagai pekerja kasar. Adonara sendiri adalah merupakan salah satu nama daerah di Flores bagian timur-Nusa Tenggara Timur. Dalam kisah yang lain disebutkan bahwa orang Adonara ini masuk rombongan pengungsian bersama Portugis dari Pulau Ende, karena pada masa Portugis di pulau Ende, juga terdapat pengungsian dari daerah Solor termasuk Adonara ke pulau Ende. Dengan demikian pemanfaatan tenaga kerja oleh orang Portugis sudah mulai terjadi dengan jalinan hubungan melalui media agama yang terlebih dahulu yang berasal dari wilayah Adonara atau Lohayong.

Pembahasan mengenai sumber air dari Perigi ini masih menyisakan kenagan yang begitu mendalam tentang masa lampau yang menyaksikan bagaimana Portugis kemudian menjadi bagian dari bukti sejarah sampai sekarang dan kondisinya masih utuh, 
dirawat oleh masyarakat Numba. Dalam masa generasi sebelumnya sumber air dari perigi menjadi tempat bertemunya banyak orang dan tempat interaksi menceritakan banyak hal termasuk tentang cerita lokal putri Rendo dan sang jagoan Jari Jawa alias Husein Djayadingrat keturunan raja Demak. Namun dengan seiiringnya berjalan waktu perigi ini tidak dipergunakan lagi sehingga cerita lisan tentang keberadaan sejarah melalui pewarisan ditempat tersebut tidak dimungkinkan lagi berlangsung. Yang terjadi kemudian banyak generasi yang melupakan sejarah lokalnya sendiri.

\section{DAFTAR PUSTAKA}

Abdullah, Abdul Rahman Haji Abdullah. (1994). Pengantar Ilmu Sejarah. Kuala Lumpur: Dewan Bahasa dan Pustaka.

Abdullah, Taufik. (1982)."Beberapa aspek penelitian sejarah local"Depdikbud. Jakarta.

Andre Bagus Irshanto. (2016).Lembaran Sejarah:Book Review.. Pelayaran dan Perdagangan Kawasan Laut Sawu Abad ke 18-awal abad ke20. Vol.12.No.1 April, 2016.ISSN: $1410-4962$

D.G.E Hall. (1988). Sejarah Asia Tenggara, Surabaya: Usaha Nasional.

Helius Sjamsuddin, (2012), Metodologi Sejarah, Yogyakarta : Ombak

Http:// Zyma Multi Media com/2017 diakses pada 15 April 2018

I.H.Doko, (1973), Nusa Tenggara Timur dalam kanca Perjuangan. Kupang

Kartodirdjo, Sartono. (2005). Pendekatan Ilmu Sosial Dalam
Metodologi Sejarah". Jakarta: Gramedia Pustaka Utama.

Muhamad Murtadho. (2015). Jurnal Lektur Keagamaan, Vol.13, No.1, 2015. Hal: 237-264.

P. Lame Uran. (1961). Sejarah Perkembangan Misi Flores Dioses Agung Ende, Ende : Nusa Indah

Sugiyono. (2008). Metode Penelitian Kuantitatif Kualitatif dan $R N D$, Bandung: Alfabeta

Suhartono W. Pranoto. (2010). Teori dan Metodologi Sejarah, Yogyakarta: Graha Ilmu

Wasino. (2009). Pokok-Pokok Pikiran untuk Penulisan Sejarah Lokal. Makalah Sarasehan Koordinasi dan Curah Pendapat Penguatan Sejarah Lokal untuk Meningkatkan Wawasan Kebangsaan Deputi Menko Kesra Bidang Koordinasi Kebudayaan, Pariwisata,Pemuda dan Olah Raga. Patra Jasa Semarang, 24 Maret 2009. 